Article

\title{
The EU Circular Economy and Its Relevance to Metal Recycling
}

\author{
Christian Hagelüken ${ }^{1, *}$, Ji Un Lee-Shin ${ }^{2}$, Annick Carpentier ${ }^{3}$ and Chris Heron ${ }^{3}$ \\ 1 Umicore, Hanau 63457, Germany \\ 2 Umicore, Brussels 1000, Belgium; JiUn.LeeShin@eu.umicore.com \\ 3 Eurometaux, Brussels 1000, Belgium; Carpentier@eurometaux.be (A.C.); Heron@eurometaux.be (C.H.) \\ * Correspondence: christian.hagelueken@eu.umicore.com; Tel.: +49-618-159-4294
}

Academic Editors: Michele Rosano and Julie Hill

Received: 6 June 2016; Accepted: 18 July 2016; Published: 27 July 2016

\begin{abstract}
This paper provides an overview of ongoing European policy actions to improve the circular management of non-ferrous metals. After explaining why metals are at the center of the European Union's circular economy initiative, the authors outline a number of issues that still need tackling to "close the loop", and prevent Europe's metals from being landfilled, incinerated, or exported without guarantee of high-quality treatment. Electronic waste is focused on in detail during this analysis, because of the special challenges in environmentally sound recovery of smaller quantities of valuable and precious metals. In particular, the authors find that a mandatory certification scheme for recyclers of electronic waste, in or out of Europe, would help to incentivize high-quality treatment processes and efficient material recovery. More generally, the article finds that the European Commission's waste legislation proposals and Action Plan begins to address key challenges, provided the requirements are implemented strongly and consistently across Member States. In particular, it is crucial that EU policy establishes level playing field conditions for European metals recyclers
\end{abstract}

Keywords: metals; recycling; circular economy; electronic waste; WEEE (waste electrical and electronic equipment); EU; policy; resource efficiency

\section{The EU Circular Economy Package December 2015}

After the financial crisis, in 2010 the European Commission put forward its 10-year "Europe 2020" strategy [1] for improving and boosting EU competitiveness and employment. A resource efficient Europe was identified as a main engine for sustainable growth, by bringing major economic opportunities, improvement of productivity, cutting costs and increasing competitiveness. Since then, the Commission has published the Roadmap to a Resource Efficient Europe [2], giving long-term policy guidance on increasing resource productivity and decoupling growth from resource use, taking into account environmental impacts. From the Roadmap, the most central policy action proposal to date on resource efficiency has been the circular economy package tabled on 2 December 2015 [3].

The European Commission had initially adopted an earlier proposal in July 2014 [4] (Figure 1), which was withdrawn to make means for a more ambitious motion to include more than just waste management. 


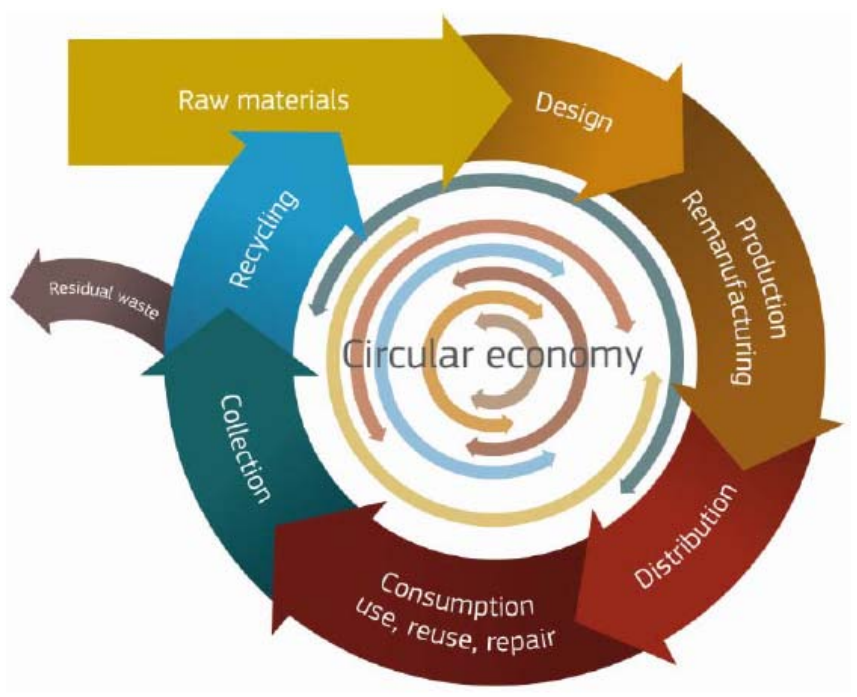

Figure 1. Towards a circular economy: A zero waste programme for Europe.

Therefore, on 2 December 2015, the European Commission presented its new Package proposal, consisting of: (1) a communication with an action plan, establishing measures with a timeline covering the whole cycle: From production, and consumption to waste management and market for secondary raw materials [3]; and (2) the revised legislative proposals on waste including the general Waste Framework Directive [5], the Landfilling Directive [6], and the Packaging and Packaging Waste Directive [7].

The European Commission defines circular economy as a transition "where the value of products, materials and resources is maintained in the economy for as long as possible, and the generation of waste minimized" [3]. Metals, including Critical Raw Materials, are a central element in the package and an ideal candidate for a circular economy as they are eternally recyclable, and secondary metals do not face downcycling or quality issues. Their comprehensive recycling and reintroduction into new lifecycles helps to secure Europe's access to metals; a key building block for a competitive economy. There are many examples where metal recycling rates are already very high: precious metals in jewelry and industrial process catalysts, steel, and base metals such as aluminum, copper and lead. However, there is significant room for improvement for many other non-ferrous metals, especially precious and specialty metals (the latter sometimes also referred as "minor metals"), which could be recovered more effectively from industrial residue streams, and end-of-life consumer goods, such as vehicles, electronic applications, or rechargeable batteries. This does not mean to strive for a 100\% recycling of all metals, as technical and economical limits need to be considered. As discussed in Reference [8] an optimum mix of secondary and primary metals supply exists. Recovering the last bits of metals from complex and low-grade materials can become more energy intensive than supplying these from primary sources. However, in most cases, the recovery of secondary metals from products/materials is far less energy intensive than their mining, as the metal concentration in many products is higher than in ores, especially in the case of precious and specialty metals (e.g., in electronic products). As mining conditions are expected to become more difficult (lower ore grades, more complexity, greater depths, etc.) the optimum mix will move towards an increasing share of secondary metals [8].

The focus of this paper will be on the existing challenges to improve the circular management of metals, and the measures needed to create the necessary framework conditions to support this. It will also identify how the circular economy package can support high-quality recycling of metals under level playing field-conditions, and incentivize material recovery. 


\section{A Circular Economy for Metals-Benefits, Opportunities, Challenges}

Unlike other raw materials, such as fossil fuels or food, metals are not consumed. Since they do not lose their intrinsic properties during recycling, metals can be used and re-used multiple times, maintaining their quality and functionality. In this sense, metals are a material with permanent characteristics that can be qualified as a permanently available resource, as long as they remain within the planet boundaries, and are not dissipated into environments where their recycling is not feasible for technical-economic reasons [8]. Metals are essential components in key sustainable innovations, including low-carbon transport, renewable energies and digital communications.

Demand for raw materials will increase alongside higher market penetration of these applications, as well as the increasing global population and its middle class. This has created two major challenges within the EU: Securing cost-efficient and sustainable access to raw materials, and increasing resource efficiency. Recycling provides a highly-efficient way of reintroducing valuable materials back into the economy, and, by doing so, tackling the key strategic challenges, while lowering environmental impacts and energy intensity of materials supply.

Metals recycling has significant benefits, as are summarized below [9]:

- Substituting primary raw materials. Europe produces only about $3 \%$ of the primary raw materials it needs for metals production, while Europe's urban mine offers a great potential to recycle more, especially technology and critical metals.

- Reducing environment and $\mathrm{CO}_{2}$ impacts of the production of secondary raw materials compared to primary material. Recycling saves up to 20 times the energy needed to produce metals and reduces the impact on water, air, soil, and biosphere.

- Reducing dependency on imported materials and secured supply of valuable materials, some of which are critical materials (metals that are important to the EU economy and show a supply risk).

- Avoiding landfill and incineration of metals, which is not only a loss of valuable raw materials, but also generates impacts on the environment.

- Supporting economic activities in Europe at the different stages of the metals recycling value chain (collection, pre-processing and end-processing), and in downstream industries thanks to the security of supply.

The growing demand for metals, however, cannot be met by recycling alone. Primary (mining) and secondary (recycling) supply will remain complementary in the future. Due to the permanent nature of metals and the long lifetime of some metal bearing products and infrastructures (which can stay in stock for tens or hundreds of years), we have been building up a significant anthropogenic stock, creating a potential future urban mine. Setting up a circular economy means that at the end of these products' lives-whenever and wherever this will take place-they need to be properly and efficiently recycled. Typically, consumer goods, such as electrical and electronic applications, and rechargeable batteries have relatively short lifecycles. They also contain a number of valuable and critical metals.

Today, advanced metallurgical recycling technologies exist for such complex products, so technically circularity can be achieved for a high number of their metals. The circular economy package can play an important role to support quality circular management.

The objective of a "circular economy" is quite clear: A circle will only be closed if materials physically find their way into new product lifecycles. In line with the waste hierarchy, the priority should be to maintain products and materials in the economy as long as possible through waste prevention and reuse. However, products will eventually reach their end-of-life and access to these for recycling, prevention of illegal or dubious waste exports, and use of best available recycling technologies need to be ensured.

There are various challenges that need to be addressed. Collection of end-of-life appliances or residue streams is a necessary prerequisite to allow recycling, but it is not sufficient. The next step is to ensure that products and materials are treated in high quality processes along the entire 
value chain, so as to be able to recover a wide range of metals with good yields and with good environmental performances, including safe elimination of hazardous substances. The growing complexity of products makes this increasingly challenging and there are some limitations to recover "all" metals from complex products [10]. As metal cycles are complex and interdependent a good managing of the overall system is crucial. For example, base metals such as lead and zinc solve key functions in certain products but, increasingly, they are linked in concert with other base metals, copper, nickel and cobalt, and with a multitude of special and precious metals in today's products and infrastructure. At the products' end-of life, in most cases, the recovery of precious and special metals is closely linked to the extractive metallurgy for base metals, i.e., the latter playing an enabling role to close the loop for the former. The understanding of this "Web of Metals" and the existing of a state-of-the-art metallurgical recycling infrastructure, hence, is a key prerequisite to achieve a circular economy [11].

In addition to the logistical, technical and environmental constraints, there are also economic challenges. High quality recycling entails costs that need to be covered. Ideally, the value of the recoverable materials matches the costs of the entire recycling treatment chain. If this is not the case, the gap needs to be bridged through other means (e.g. through recycling fees or innovative business models). Hence, especially at times of depressed raw material prices, the legislator needs to establish supportive framework conditions and a level playing field to allow high quality recycling of complex products containing valuable materials, and close the economic gap where needed.

\section{The Recycling Value Chain-The Case of Consumer Electronics}

The recycling value chain can be defined as the sequence of operations leading to the recovery of materials from waste. These operations include (1) collection, the beginning of any waste management process; (2) preparation for material recovery, which covers manual and/or mechanical operations and physical sorting; and (3) material recovery, which consists of chemical, physical and/or metallurgical operations, but does not include incineration for energy recovery and the reprocessing into materials that are to be used as fuel. The recycling value chain ends when the waste is reprocessed into products or materials, which do not require any further processing whether for the original or other purposes [12]. In other words, final outputs of a recycling chain are metals and materials in a sufficiently pure quality that are capable of replacing primary metals (i.e., originating from mining chains) as input raw materials for the manufacturing of new products.

The recycling value chain is illustrated in Figure 2 for the case of electronics recycling, which requires a complete process chain from collection to sorting and dismantling into separate components containing valuable metals (pre-processing), and then to a subsequent final metallurgical processing (end-processing). In this last end-processing step, valuable metals are extracted usually in a combination of pyrometallurgical and hydrometallurgical processes and purified to pure metals, which are then delivered back to the market for new product lives. The actual physical metal recycling takes place at the very end of the chain, but the preceding steps are crucial for directing the fraction containing the various metals to quality final recovery processes. Figure 2 illustrates this recycling chain with an estimate on order of magnitude on number of actors worldwide.

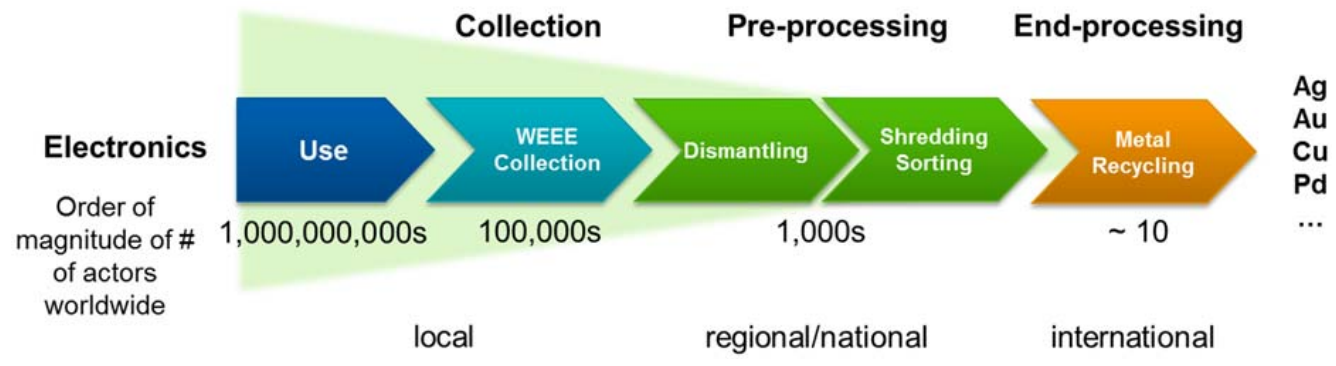

Figure 2. Recycling value chain for electronic waste. 
"Mono-substance" waste streams, such as glass or steel scrap, are generally available in large quantities and contain little or no hazardous substances. Recycling of these streams is technically relatively simple. To the contrary, complex "poly-substance" end-of-life products, such as consumer electronics, contain a wide range of different materials, including hazardous substances. These streams require a different and more complex recycling chain treatment. Whilst for mono-substance streams, the focus is on cost optimization and mass and volume recovery, for complex poly-substance streams, it is essential to focus on environmentally sound value recovery of materials that are often present in low concentrations. For example, the mass of precious metals contained in electronics is negligible, but they represent a significant share of the intrinsic material value and of the ecologic footprint [9].

Recent developments in electronic products further increase these challenges. While sales numbers for many consumer products are still rising, their rapid change in design and composition, progressive miniaturization and complexity makes recycling of these products increasingly difficult. Advanced recycling technology can to a certain extent cope with such developments but for the case of a multitude of different elements, often in combinations that do not exist in nature and partly intensely interconnected and with low concentrations, the laws of thermodynamics set technical limits [10]. At the same time, substitution and thrifting in precious metal content have led to a decrease of intrinsic material value per device [13].

An ideal recycling value chain for consumer electronics, firstly, needs to ensure separate high collection, notably thanks to incentives and consumer awareness, combined with appropriate infrastructures that facilitate access of end-of-life products for recycling. However, one issue is that high priced small electronics (e.g., mobile phones or laptops) are often hoarded in households [14].

It is also essential that collection and recycling systems ensure traceability to prevent waste streams being diverted into the wrong channels, dumps or poor quality treatment processes, where their valuable metals will be lost and the environment damaged [12]. Here, pre-processors also have an important role in dismantling and separating such complex products, ensuring they are transferred to high-quality end-processors. A set of technical guidelines and standards has been developed to define effective and quality pre-processing (see Section 5 ).

The challenging trade-off is between a cost-effective recovery of large volume materials and a gradual recovery of critical and valuable materials present in small quantities. Nevertheless, valuable and critical metals are spread across various fractions and partial loss is inevitable in case of highly complex products, $100 \%$ recovery of "all" metals is not achievable [10] (see Section 1). However, just cherry picking the few most valuable metals-e.g., gold and copper in case of electronic waste-while emitting hazardous substances is certainly not the right approach from a sustainability and circular economy perspective.

Finally, subsequent final metallurgical processing needs to take place at state-of-the-art end-processors. High-quality processes are required to recover high metal yields, and to safely eliminate hazardous components and emissions. It is also important to note that while collection is conducted on a local and regional scale, pre-processing mostly makes use of regional and interregional operations (see Figure 2). This differs from the final step, which requires sophisticated large-scale integrated metallurgical plants, requiring significant investments and sufficient feeds to operate, especially for the recovery of precious and special metals. Economies of scale are crucial to ensure that the costs associated with recycling of consumer waste electronics are kept at a reasonable level. Here, only a limited number of such plants can treat materials sourced internationally. Therefore, a good cooperation and coordination of stakeholders along the recycling chain is essential to be overall successful in closing the loop. The weakest step in the chain determines the overall performance, i.e., highly efficient end-processing will be of little relevance if collection is weak or pre-processing is not capable of channeling the fractions with valuable and critical metals into the most appropriate metallurgical recycling processes. Of specific relevance are technical and economical optimization at the interfaces between pre-processing and end-processing and the facilitation of shipments along the chain to the downstream quality treatment plants. 


\section{Recycling Drivers and Success Factors-Specific Challenges for Resource Relevant Consumer Products}

The case of consumer electronics shows the challenges society faces to close the loops. Nevertheless, there are other product examples where circularity already works well. Thus, in order to identify the appropriate frame conditions for a broader circular economy approach, it is worth having a closer look at recycling drivers and success factors.

Probably, the most outstanding example of circularity is gold in jewelry, artifacts, coins or ingots, where the high metal and emotional value provides sufficient incentives that prevent losses. Based on various data sources and deep insights into the precious metals markets, the authors estimate that, of the approximately 180,000 tons of gold so far mined in mankind's history, more than $90 \%$ is still in use, respectively, in stock.

However, not all precious metals are recycled efficiently. Overall, average recycling rates for precious metals are above 50\%, with huge differences across applications [15]. For example, from chemical and oil refining process catalysts, over $90 \%$ of the precious metals contained therein are recovered, even in cases of long lifecycles of over 10 years [9,15]. Such a closed cycle is typically taking place in a business-to-business (B2B) environment, with no private consumers involved in its different steps. The user of the metal-containing product (e.g., the chemical plant) returns the spent product directly to a refiner who recovers the metals and returns them to the owner for a new product cycle. In most cases, the metals remain the property of the user for the entire cycle and the metal-refiner conducts recycling as a service. With such a set-up, the whole cycle flow becomes very transparent and professionally managed by industrial stakeholders, resulting in very small metal losses. Recycling is from the beginning planned in as an integral part of the business model, which is purely market driven.

Another example is automotive catalysts, which contain platinum group metals (PGM). From composition and metal concentration, they are very similar to chemical process catalysts $(0.2 \%-0.3 \%$ PGM on a ceramic matrix), but PGM recycling rates are $60 \%-70 \%[9,15]$. Compared to many other metal applications this is still a very high recycling rate, driven by a high intrinsic value and easy disassembly from a car. However, metallurgical recovery rates for PGM from automotive catalysts may be over $95 \%$. The gap to the $60 \%-70 \%$ effective recycling rate is caused among other factors by exports of end-of-life (EoL) cars to regions with insufficient recycling infrastructures, and by a long and opaque recycling value chain.

Less promisingly, electronic wastes have average precious metal recycling rates below $15 \%[9,15]$ due to the reasons elaborated in the previous chapter. Precious metals recovery rates would again be over $95 \%$ if all waste materials were efficiently transferred to state-of-the art metallurgical refineries.

In summary, in open cycles taking place in a business to consumer (B2C) environment, metal losses are significantly higher due to other reasons than what is caused by the technical recycling process itself. In B2C applications, ownership of the metals changes each time a transaction occurs, transparency is low, businesses often do not follow an industrial logic, and, hence, results in higher metal losses than in $\mathrm{B} 2 \mathrm{~B}$ closed loop systems. To improve overall recycling rates, we need frame conditions that contribute to move from open B2C business models towards closed B2B cycles [16].

Beyond the intrinsic value and the business models applied, a number of other factors impact successful circularity. These can be grouped in product-intrinsic and external factors:

Intrinsic factors comprise of material value (example jewelry), complexity/heterogeneity of a product (incl. product design and ease to access/disassemble key components), the presence or absence of hazardous substances, the business model type/lifecycle type (B2C, B2B), and the product's transferability between users (e.g., mobile phone versus coffee machine).

External factors comprise of collection infrastructure (ease of handing in an end of life product) and external incentives (e.g., leasing, deposit systems), appropriate waste legislation (including the effectiveness of monitoring and enforcement), and stakeholder behavior and motivation (awareness and cultural habits, emotional links to a product, etc.). The latter is of significance, not only for consumers, but for all other stakeholders involved: How serious do manufacturers and retailers strive 
to close the loop, how well are EPR systems set up and maintained, to which extent do authorities engage in monitoring and enforcement, and how seriously do municipalities, waste management and recycling companies along the chain strive for comprehensive collection and high quality repair and recycling? Business ethics also play an important role, as sound, effective and environmentally compliant recycling is usually more costly than "quick and dirty" approaches.

Figure 3 compares qualitatively to which extent these different factors impact the overall success of circularity in Western Europe for some product examples. It needs to be noted that interdependencies between these factors exist and usually the factor combination is decisive for the overall impact. Take, as example, chemical catalysts, WEEE (waste electrical and electronic equipment) and lead acid car batteries, all of which contain hazardous elements. For PGM chemical catalysts, the B2B business model type, in combination with the high material value, drives a well-managed cycle within industrial players, capable of coping with the hazardous characteristics. In the case of car batteries, the hazardous properties triggered legislation on proper battery handling and recycling, in some countries supported by deposit fees. For a private consumer, a spent car battery is valueless (without losing the deposit he paid), hence, will handle it as waste if infrastructure is accessible. This has led to a widely closed loop for car batteries-as long as they are not exported outside Europe along with EoL vehicles. This is different with some small WEEE that has an emotional value to consumers. A classic example is a mobile phone: It is small and thus can be easily stored or thrown in a waste bin; due to its purchased value and personal attachment (personal data, photos, etc.), it is somehow regarded as "precious"; it can be sold as a second hand good (high transferability). Therefore, establishing a closed loop for mobile phones becomes very difficult as long as no incentives, such as leasing business models or deposit systems, exist. However, not all WEEE are the same, and size plays a difference/role-a non-functioning fridge is just a burden for the consumer-as well as transferability linked with attractiveness, e.g., in Europe, the market for second-hand coffee machines is small, and, once a machine is dysfunctional, most consumers will dispose of it.

\begin{tabular}{|l|c|c|c|c|c|c|}
\hline & $\begin{array}{c}\text { Glass, } \\
\text { paper, } \\
\text { PET }\end{array}$ & $\begin{array}{c}\text { precious- } \\
\text { metal } \\
\text { jewellery }\end{array}$ & $\begin{array}{c}\text { PGM- } \\
\text { chemical } \\
\text { catalysts }\end{array}$ & $\begin{array}{c}\text { Ge bearing } \\
\text { industrial } \\
\text { residues }\end{array}$ & $\begin{array}{c}\text { WEEE, } \\
\text { (ELV) }\end{array}$ & $\begin{array}{c}\text { Pb car } \\
\text { batteries } \\
\text { (Germany) }\end{array}$ \\
\hline intrinsic factors & & & & & & \\
\hline Material value & 0 & ++ & ++ & + & $(+)$ & $(+)$ \\
\hline complexity / heterogeneity & - & - & 0 & 0 & ++ & 0 \\
\hline hazardous substances contained? & - & - & 0 & 0 & + & ++ \\
\hline business model / lifecycle type & $\mathrm{B} 2 \mathrm{C}$ & $\mathrm{B} 2 \mathrm{C}$ & $\mathrm{B} 2 \mathrm{~B}$ & $\mathrm{~B} 2 \mathrm{~B}$ & $\mathrm{~B} 2 \mathrm{C}$ & $\mathrm{B} 2 \mathrm{C}$ \\
\hline Product transferability between users & 0 & 0 & - & - & ++ & 0 \\
\hline
\end{tabular}

\begin{tabular}{l}
\begin{tabular}{l|c|c|c|c|c|c|}
\hline external factors & & & & & & \\
\hline Collection-infrastructur & ++ & & & & 0 & 0 \\
\hline extemal collection incentives & (deposits) & & & & & deposit \\
\hline legislation / monitoring / enforcement & & & + & & 0 & + \\
\hline stakeholder behavior \& motivation & & $\mathrm{X}$ & & & $\mathrm{X}$ & \\
\hline
\end{tabular} \\
\hline
\end{tabular}

* in relation to entity of resource relevant materials contained in a product

- low / no o medium / partly + high / yes

$\mathrm{B} 2 \mathrm{C}$ consumer goods, open product cycles, low transaprency on material flows

B2B industrial users, closed product cycles, relatively high transparency on material flows

Figure 3. Qualitative assessment of factors impacting the circularity for some selected products [17].

As expected, circularity is well achieved for the B2B examples of chemical process catalysts with PGM or germanium bearing industrial production scrap (e.g. from Ge wafer production), and, for B2C, precious metal jewelry. Products in B2C lifecycles, as well as certain B2C products with-from 
a consumer's perspective-have relatively low value, such as paper, glass and PET (polyethylene terephthalate) bottles, are very well recycled, mainly due to low product complexity, a very well established collection infrastructure, and the absence of any "emotional links" to these products. In some countries (e.g., Germany), collection of PET bottles and certain glass bottles is incentivized by deposit systems. WEEE shows the worst results due to challenges from almost all factors. The intrinsic and external factors described above, and their relative scoring in the table, are derived from over 20 years' experience of the main author in the field of metals recycling. It would be interesting to further analyze these empirical observations, and to elaborate on interdependencies, as well on the interplay of physical/technical, economical and behavioral/cultural influences. However, this will be (research) work of its own and goes beyond the scope of this paper.

Summing up, the degree of circularity of products depends on a complex range of impact factors, as illustrated in Figure 3. In some cases-e.g., jewelry, valuable products in a B2B environment-market forces alone are sufficient for success. However, especially for complex consumer products that contain a mix of valuable and hazardous materials market forces alone are not sufficient, but appropriate, policy and legislation is crucial to improve the current status of low circularity.

\section{Quality Recycling Based on Process Standards and Certification-A Cornerstone for Closing the Metals Loop}

To create a global level playing field on recycling activities and support Europe's competitiveness in the field, high quality recycling processes and practices are needed. "Quality recycling" may be understood as a minimum level of quality of the recyclate/output material and/or a minimum level of quality of the treatment process, including the existing depollution requirements at EU level under the Waste Electrical and Electronic Equipment Directive [18].

As mentioned previously, metals have intrinsic properties during recycling, thus, can be used multiple times and re-used maintaining their quality and functionality. Therefore, for metals we need quality recycling through proper treatment using state-of-the-art processes and facilities. For complex waste streams, such as electronic waste, due to the content of hazardous components, the EU Directive on WEEE outlines minimum selective depollution treatment and mandates the development of state-of-the-art minimum standards for its treatment [18]. Furthermore, the directive allows that the treatment operation may be undertaken outside the respective Member State or the EU, provided that the shipment of WEEE is in compliance with existing rules, and treatment takes place in conditions that are equivalent to EU requirements [18]. However, depollution performance, the extent to which raw materials are recycled, the level of safety, health and environmental measures and control procedures differ considerably not only on a global scale but also within the EU.

The report on "Countering WEEE Illegal Trade" (CWIT) that was financed by the European Commission and conducted by Interpol found that in Europe only 35\% (3.3 million tons) of all the e-waste discarded in 2012, ended up in the officially reported amounts of collection and recycling systems. The other $65 \%$ (6.15 million tons) was either exported (1.5 million tons), recycled under non-compliant conditions in Europe (3.15 million tons), scavenged for valuable parts (750,000 tons) or simply thrown in waste bins (750,000 tons), meaning that there is a serious economic loss of materials and resources directed to compliant e-waste processors in Europe [19]. Hence, non-compliance of the WEEE Directive, as well as the Waste Shipment Regulation, which also sets the conditions for exports of waste to non-OECD countries, notably with view to ensuring environmentally sound management of waste, becomes problematic. Dumping or low quality sub-standard treatment ("backyard recycling"), not only has negative impacts on human health and the environment, but also leads to significant pressure on recycling prices and disturbs a fair level playing field, as such operations externalize environmental and social costs. This makes it difficult for compliant recyclers to achieve a stable capacity utilization and to invest in new processes or capacity expansion, which can delay or even prevent the medium- and long-term harvesting of the EU's potential on secondary raw materials. 
Under mandate $M / 518$, the European Commission requests that European standardization organizations develop European standards for treatment, including recovery, recycling and preparing for re-use of WEEE [20]. CENELEC, the European Committee for electrotechnical standardization, is currently developing a series of such European standards and technical specifications (EN 50625 series), reflecting the state-of-the-art in recycling covering the whole value chain, as well as environment, health, governance and process efficiency provisions. Nevertheless, there is no obligation or legal requirement for the mandatory implementation of finalized standards and technical specifications of the EN 50625 series, and only a few Member States, such as France, Ireland and the Netherlands, have decided to comply with these standards. Therefore, this situation not only creates leakage of WEEE to Member States, where standards remain optional, but distort a significant part of the WEEE stream, as it continues to be treated in sub-optimal conditions. Additionally, the existing WEEE Directive does not set sufficient incentives for the recovery of precious metals from WEEE, as recycling targets are weight based, and the existing point of measurement for recycling does not account for the output of recovered materials.

One solution would be to make it compulsory for WEEE recyclers to comply with the EN 50625 series of standards and technical specifications. Recyclers outside of Europe should also be required to treat EU WEEE exports under equivalent conditions.

Putting in place a certification scheme with a third party audit would verify harmonized enforcement across the EU and outside. Such legal requirements are necessary to ensure that the circular economy for complex waste streams, such as WEEE, will be closed physically, where recycled materials are re-injected in new product lifecycles, and, economically, where costs match recycling treatment.

\section{The Essential Role of Policy and Legislation}

When tackling the challenges and barriers to a more circular use of metals in Europe, a systemic approach is required, using a combination of complementary measures across the value chain. As elaborated in Section 4, especially for products with lower intrinsic material value or other missing attractiveness to recycle, policy and legislation play key roles. Without a WEEE directive, presumably the bulk of our electric and electronic wastes would still go to landfills or to incineration. The same is valid for, e.g., batteries or plastics. Paper and glass are only recycled at high rates due to the comprehensive infrastructure that has been set up in most European countries, financed by various fee systems. However, one-size-fits-all policy requirements will not be effective in realizing the circular economy model across all European sectors. The regulator can adopt measures that will help address the challenges identified. The circular economy package is a step in the right direction, as it addresses some of the issues and promotes the recovery of materials from waste. Below is an overview of the main and general key measures that could address the above-mentioned challenges for metals, which have been put together by the European Non-Ferrous Metals Association (Eurometaux) [8]. The table (Table 1) aims to pinpoint several issues in the legislative package, without going into an in-depth policy analysis or discussion on legal wording, as this is beyond the scope of this paper. Several measures are already included in the present circular economy package proposal from the European Commission, while others require further development or are under discussion, such as the point of measurement for the recycling targets (see Figure 4). At present, the European Commission's proposal is undergoing co-decision procedure between the European Parliament and the Council. 
Table 1. Existing challenges and possible solutions in the Circular economy Package.

Challenge
Inconsistent measurement of recycling rates
Varying interpretation of what "recycling" means and how it
should be measured. Currently, Member States interpret
"recycling" and calculate their recycling rates differently,
creating inconsistencies. Some base their recycling rates on
collected waste, even though it covers waste that will be
exported after collection or sorting, incinerated or landfilled,
which does not incentivize the recovery of materials.

Solution

\section{A single method for measuring recycling rates, at the input to final} recycling process

The Commission proposal on the rules to calculate the attainment of the recycling targets is understood as the "weight of the input waste entering the final recycling process", which further incentivises the recovery of materials from waste reflecting reality of what recycling should be.

"Final recycling process" is defined as "the recycling process which begins when no further mechanical sorting operation is needed and waste materials enter a production process and are effectively reprocessed into products, materials or substances" (See Figure 4 below table)

This means that a final recycling process generates output in a sufficiently pure quality, capable of replacing primary materials. In addition, independent of where finally the point of measurement will take place (statistical data availability plays here a role as well) it is crucial to keep the definition of final recycling process in order to underline that the circle can only be closed if products/materials have passed the recycling chain to the very end.

Suboptimal end-of-life collection schemes.

Collection is the first step of the recycling value chain.

If collection is not performed efficiently the recycling rate cannot increase significantly. The efficiency of the collection schemes vary widely across Europe.

\section{Landfill and incineration}

Landfilling and incineration of post-consumers goods. Too many end-of-life products which contain valuable materials, sometimes even critical, are landfilled or incinerated.

Illegal waste exports, both legal and illegal

\section{Minimum requirements for Extended Producers Responsibility}

The Commission's proposal to support separate collection and define minimum requirements for extended producer responsibility (EPR) will help improve collection. The EPR schemes should also cover the entire cost of waste management, including the final recycling process

\section{Target to reduce landfill to $10 \%$}

The objective to reduce the landfilling of recyclable waste to $10 \%$ is essential to support recycling. Enforcement at Member State level is crucial. Incineration with energy recovery is a complementary option that is lower than recycling in the waste hierarchy but that has its merit in cases where recycling is not feasible.

\section{Stronger controls and a requirement for waste exports to be recycled under} 'equivalent conditions'

Different measures can be instrumental in fighting against illegal shipments, including

(Illegal) Exports of waste due to high intrinsic value of certain scrap and embedded energy content. Exports of hazardous waste are often labelled as second-hand goods, and waste for disposal as waste going to recovery.

- Harmonised control of shipments at harbours to avoid "port hopping"

- Identification of second hand goods in customs declarations to facilitate targeted controls

- In the case of complex waste streams (e.g., WEEE and waste batteries) introduce a requirement that secondary materials may only be exported if a certified final processor is duly identified.

The Commission recognises the need to combat illicit shipment and step up enforcement of the revised waste shipment regulation.

\section{No level playing field for quality recyclers}

Recycling processes must meet minimum quality criteria and these need to apply across the recycling value chain in Europe and elsewhere

\section{A focus on mass not value}

As EU waste policies traditionally focus on volume and weight, certain valuable materials in end-of-life products are not yet sufficiently targeted in collection and recycling.

\section{Barriers to industrial symbiosis \& recycling}

There are a number of barriers to intra-EU shipments of waste, end-of-life products and by-products for recycling. This includes the non-harmonised status of waste and by-products across Member States, the use of national waste codes or the lack of appropriate codes for given waste, the overly complex and lengthy procedures (notification and transit) and in some cases the inappropriate implementation of the proximity principle.

\section{Effective regulation of hazardous substances.}

Because they are naturally occurring substances a metal free environment is by nature impossible. A sheer ban of hazardous substances would decrease the amount of waste recycled in Europe, and be an incentive to landfill, export materials and import more materials and products

\section{Certification of treatment facilities}

The Circular economy package is not sufficiently ambitious as it merely proposes the "promotion of industry-led voluntary certification of treatment facilities". A mandatory certification scheme would ensure equivalent and fair conditions. (see Chapter 5)

\section{A product-centric approach}

The proposed Action Plan rightly identifies the need to pay increased attention to the recovery of valuable and critical raw materials from end-of-life products.

It is important to treat each product according to its specificities, including material composition and the techno-economic opportunities from recycling.

\section{Measures to facilitate waste shipments in Europe}

Harmonised definitions of waste and by-products and the use harmonised EURAL codes (no separate national codes) across Member States is key. New codes should be created for waste for which no waste codes exist.

The Waste Shipment regulation provides a simplified procedure for "pre-consented recovery facilities", but does not provide much benefit in reality. It should be improved to allow fast track and immediate shipment of waste from and to pre-consented recovery facilities once the competent authorities have been notified. Control can take place at any time thanks to an easy tracking of shipments through their identification number. An electronic system would also facilitate the procedure.

\section{Effective, smart \& proportionate legislation}

End-of life products containing hazardous substances should be properly treated i.e., in respect of the legislation in place.

Legislation should be effective, smart and proportionate. It should not unnecessarily discourage the use of secondary resources, especially within the context of the EU Circular economy and global competition. We need to secure a sound risk management and avoid penalizing EU recyclers unnecessarily.

Technical and economic challenges when recycling complex products

The trend in changes in the composition and design of products raises challenges in terms of economic viability of the recycling process. In addition, an ever increasing variety of element combinations in components and products cause technical challenges and require the development of new recycling approaches.

\section{Targeted innovation support}

A targeted support to innovation supporting the recycling of complex products coupled with an increased dialogue across the value chain is needed to address this challenge.

The Commission has committed to support Circular economy developments through its research and innovation financing programme, Horizon 2020, and Cohesion Policy funs. 


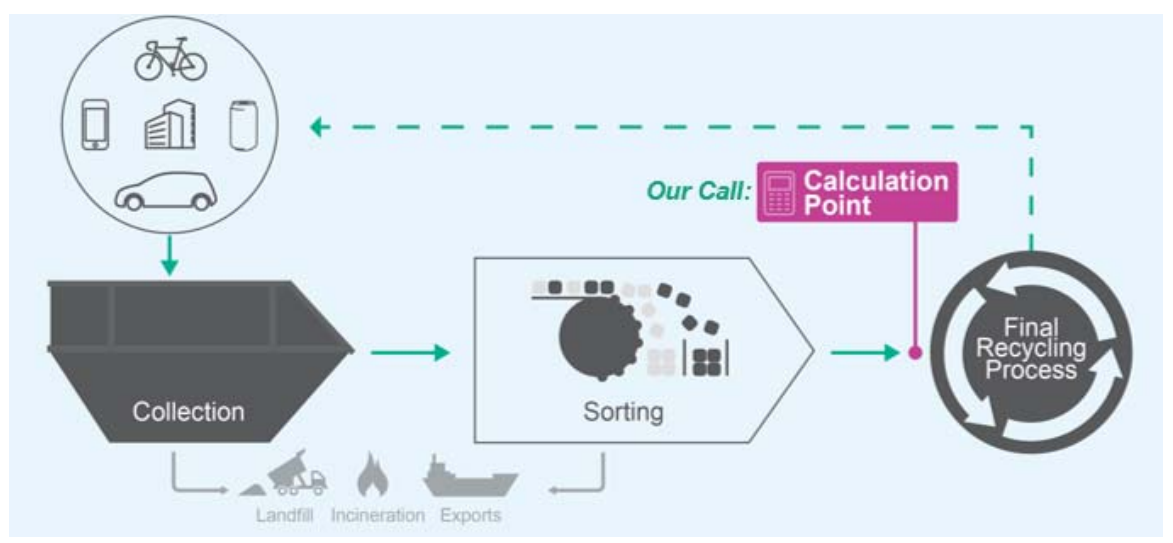

Figure 4. Final recycling process and measurement of recycling rate [21].

\section{Conclusions and Way Forward}

To conclude, metals are the perfect material for a circular economy, as they can be recycled again and again without losing their properties. However, there are a number of challenges that need to be addressed in a systemic way to ensure that Europe maintains its leading position in the recycling of base metals, and to further develop the recycling of valuable and critical metals that are present in small quantities in complex products.

The main challenges relate to accessing the waste and end-of-life products, and to ensure that quality operators recycle them. Addressing these challenges would ensure that more metals are recycled and at higher yields. It would also support the competitiveness of quality recyclers and, hence, their investments and the related job opportunities.

The European Commission's circular economy package is a step in the right direction, focusing more than ever, on the recovery of materials embedded in waste.

For the waste proposals, the Commission's ambition now needs to be maintained through the co-decision procedure, and Member States need accept the challenge of reaching ambitious targets (notably through the new point of measurement of recycling targets). Without harmonized implementation of the waste legislation, an effective European circular economy will not be possible.

It is still too early to tell whether the ambition of the European Commission's Action Plan will be translated into reality. The next three years will be crucial to implement strong regulations on areas, including resource-efficient eco-design, illegal waste exports and intra-EU waste trade.

Without comprehensive actions to address the different challenges identified in this paper, Europe will be unable to capture the full economic benefits of a circular economy. The European metals industry has invested in becoming a global recycling leader, and is committed to work with policy makers to achieve this ambition.

Author Contributions: Christian Hagelüken has taken part in conceptualizing, writing and checking the paper. Ji Un Lee Shin has taken part in writing and checking the paper. Annick Carpentier has taken part in writing and checking the paper. Chris Heron has taken part in reviewing the paper structure and checking the English.

Conflicts of Interest: The authors declare no conflict of interest.

\section{References}

1. European Commission (EC). Communication from the Commission: Europe 2020, A Strategy for Smart, Sustainable and Inclusive Growth, COM (2010) 2020 Final; European Commission (EC): Brussels, Belgium, 2010.

2. European Commission (EC). Communication from the Commission to the European Parliament, the Council, the European Economic and Social Committee and the Committee of the Regions: Roadmap to a Resource Efficient Europe, COM (2011) 0571 Final; European Commission (EC): Brussels, Belgium, 2011. 
3. European Commission (EC). Communication from the Commission to the European Parliament, the Council, the European Economic and Social Committee and the Committee of the Regions: Closing the Loop-An EU Action Plan for the Circular economy. COM (2015) 614/2; European Commission (EC): Brussels, Belgium, 2015.

4. European Commission (EC). Communication from the Commission to the European Parliament, the Council, the European Economic and Social Committee and the Committee of the Regions: Towards a Circular economy: A Zero Waste Programme for Europe. COM (2014) 0398; European Commission (EC): Brussels, Belgium, 2014.

5. European Commission (EC). Proposal for a Directive of the European Parliament and of the Council Amending Directive 2008/98/EC on Waste. COD 2015/0275; European Commission (EC): Brussels, Belgium, 2015.

6. European Commission (EC). Proposal for a Directive of the European Parliament and of the Council Amending Directive 1999/31/EC on the Landfill of Waste. COD 2015/0274; European Commission (EC): Brussels, Belgium, 2015.

7. European Commission (EC). Proposal for a Directive of the European Parliament and of the Council Amending Directive 94/62/EC on Packaging and Packaging Waste. COD 2015/0276; European Commission (EC): Brussels, Belgium, 2015.

8. Wellmer, F.W.; Hagelüken, C. The Feedback Control Cycle of Minerals Supply, Increase of Raw Materials Efficiency, and Sustainable Development. Minerals 2015, 5, 815-836. [CrossRef]

9. Hagelüken, C. Recycling of (Critical) Metals: In Critical Metals Handbook; Gunn, G., Ed.; Wiley: Oxford, UK, 2014.

10. UNEP. Metal Recycling-Opportunities, Limits, Infrastructure-A Report of the Working Group on the Global Metal Flows to the International Resource Panel; United Nations Environment Program: Paris, France, 2013.

11. Reuter, M.A.; Matusewicz, R.; Van Schaik, A. Lead, Zinc and their Minor Elements: Enablers of a Circular economy. World Metal.-ERZMETALL 2015, 68, 132-146.

12. Eurometaux. Proposed Measures to Ensure an Effective Circular Economy. Available online: http://www.eurometaux.org/DesktopModules/Bring2mind/DMX/Download.aspx?Command= Core_Download\&EntryId=8461\&PortalId=0\&TabId=57 (accessed on 6 June 2016).

13. Van Kerckhoven, T. Optimizing (precious) metals recovery out of electronic scrap. In Proceedings of the Electronics Recycling, Singapore, 13 November 2014.

14. Nokia Corporation. Global Consumer Survey Reveals that Majority of Old Mobile Phones Are Lying in Drawers at Home and Not Being Recycled; Nokia Corporation: Helsinki, Finland, 2008.

15. UNEP. Recycling Rates of Metals-A Status Report: A Report of the Working Group on the Global Metals Flows to the International Resource Panel; United Nations Environment Program: Paris, France, 2011.

16. Hagelüken, C.; Buchert, M.; Ryan, P. Materials Flow of Platinum Group Metals in Germany. Int. J. Sustain. Manuf. 2009, 1, 330-346. [CrossRef]

17. Hagelüken, C. Kreislaufwirtschaft 2015-wo Stehen wir Heute im Vergleich zu vor zehn Jahren? In Proceedings of Berliner Recycling und Rohstoffkonferenz, 16-17 March 2015.

18. European Commission (EC). Directive 2012/19/EU of the European Parliament and the Council of 4 July 2012 on Waste Electrical and Electronic Equipment (Recast). L 197/38; European Commission (EC): Brussels, Belgium, 2012.

19. Huisman, J.; Botezatu, I.; Herreras, L.; Liddane, M.; Hintsa, J.; Luda di Cortemiglia, V.; Leroy, P.; Vermeersch, E.; Mohanty, S.; van den Brink, S.; et al. Countering WEEE Illegal Trade (CWIT) Summary Report, Market Assessment, Legal Analysis, Crime Analysis and Recommendations Roadmap, 30 August 2015, Lyon, France. Available online: http:/ / www.cwitproject.eu (accessed on 6 June 2016).

20. M/518 EN Mandate to the European Standardisation Organisation for Standardisation in the Field pf Waste Electrical and Electronic Equipment (Directive 2012/19/EU (WEEE)). Available online: http:/ /ec.europa. eu/environment/waste/weee/pdf/m518\%20EN.pdf (accessed on 6 June 2016).

21. Waste Framework Directive: European Material Industries call for Measurement of Real Recycling Rates. Available online: http:/ / www.cepi.org/node/20494 (accessed on 6 June 2016).

(C) 2016 by the authors; licensee MDPI, Basel, Switzerland. This article is an open access article distributed under the terms and conditions of the Creative Commons Attribution (CC-BY) license (http:/ / creativecommons.org/licenses/by/4.0/). 